\title{
Use of health care services in seasonal affective
}

\section{disorder}

JOHN M. EAGLES, FIONA L. HOWIE, ISOBEL M. CAMERON, SAMANTHA M. WILEMAN, JANE E. ANDREW, CAROL ROBERTSON and SIMON A. NAJI

\section{Background Little is known about the presentation and management of seasonal affective disorder (SAD) in primary care.}

\begin{abstract}
Aims To determine the use of health care services by people suffering from SAD.
\end{abstract}

\section{Method Following a screening of patients consulting in primary care, 123 were identified as suffering from SAD. Each was age- and gender-matched with two primary care consulters with minimal seasonal morbidity, yielding 246 non-seasonal controls. From primary care records, health care usage over a 5 -year period was established.}

Results Patients with SAD consulted in primary care significantly more often than controls and presented with a wider variety of symptoms. They received more prescriptions, underwent more investigations and had more referrals to secondary care.

\section{Conclusions Patients with SAD are} heavy users of health care services. This may reflect the condition itself, its comorbidity or factors related to the personality or help-seeking behaviour of sufferers.

\section{Declaration of interest Funded by} the Scottish Office Department of Health and Grampian Primary Care NHS Trust.

†See editorial, pp. 394-395, this issue.
Within the past two decades, seasonal affective disorder (SAD) has been increasingly diagnosed and treated. The concept of SAD, at least initially, was viewed by some with scepticism (Eastwood \& Peter, 1988), but it has steadily gained in credence and is included in DSM-IV (American Psychiatric Association, 1994) as major depressive episodes with seasonal pattern. Winter symptoms of lowered mood, increased lethargy, increased appetite and increased sleep length are very common away from the equator (Kasper et al, 1989), giving rise to debate about the point where a dividing line between 'health' and 'illness' might most appropriately be drawn on what appears to be a normally distributed continuum. Predictably, when SAD is defined more narrowly, estimates of community prevalence are lower but still significantly high at $1.4-3.5 \%$ (Blazer et al, 1998; Eagles et al, 1999). Given these levels of community prevalence, it seems almost certain that the majority of sufferers go undiagnosed and untreated. We hypothesised that sufferers of SAD would be consulting in primary care with increased frequency, that they would often present with physical manifestations of SAD and that they would generate increased numbers of prescriptions, tests/ investigations and referrals for specialist care.

\section{METHOD}

The subjects in this study were identified first through the screening procedures described in previously published papers (Eagles et al, 1998, 1999; Andrew et al, 2001) and the service use data reported in the present paper derive from the aggregated sample from the two previous studies. Eleven large group practices based in and around Aberdeen participated, covering a total population of close to
120000 people and employing about 60 general practitioners. Patients aged 16-64 years were approached while waiting to see their general practitioner during the month of January and were invited to complete the Seasonal Pattern Assessment Questionnaire (SPAQ; Rosenthal et al, 1987). Of 7927 people attending their general practitioner, 5249 (66.2\%) adequately completed the SPAQ, and those who fulfilled the criteria for SAD on this instrument were invited for interview. Of 505 who were cases of SAD on the SPAQ, $274(54.3 \%)$ attended for interview before the end of February. Of these, 127 (46.4\%) also fulfilled DSM-IV criteria for recurrent major depressive disorder with seasonal pattern (American Psychiatric Association, 1994) and scored at least 15 on the Structured Interview Guide for the Hamilton Rating Scale for DepressionSeasonal Affective Disorder version (SIGH-SAD; Hamilton, 1967; Williams et al, 1988; Terman \& Williams, 1994), with a score of at least 6 on the atypical symptoms questions. These 127 patients, fulfilling all three sets of criteria for SAD were designated 'interview-confirmed cases'. Of these 127 patients, 123 had primary care case records available and thus were included in the present study.

Each interview-confirmed case of SAD (none of whom had been diagnosed previously with SAD) was matched by gender and by age (to within 1 year) with two subjects who had attended the same general practice during January but who scored 6 or less on the global seasonality score of the SPAQ, this score indicating that they rated themselves as experiencing little or no significant seasonal fluctuation in their well-being. These 246 people were designated as 'non-seasonal controls'. It is perhaps worth noting that although the control group rated themselves as being without meaningful seasonal fluctuation in well-being, no rating was made of their current mood and the control group was not intended to be one without possible depressive symptomatology of a non-seasonal nature.

The written and computerised primary care records of interview-confirmed SAD cases and non-seasonal controls were scrutinised. Use of health care services was recorded over a 5-year period, stretching back from May of the year in which they completed the screening procedures. The following data were recorded: 
(a) numbers of primary care consultations;

(b) symptoms presented at each consultation, which were classified, where possible, by 'bodily system' (cardiovascular, gastrointestinal, etc.); specific note was made of symptoms that previously had been described as associated with SAD, namely pain, headache, infection, tiredness/lethary, weight gain/bingeing, sleep disturbance, depression, anxiety/panic, palpitations, alcohol misuse, diarrhoea/irritable bowel syndrome and premenstrual syndrome;

(c) prescriptions issued, again classified by bodily system and sub-classified by the notations used in the British National Formulary (Joint Formulary Committee, 1999);

(d) tests and investigations ordered;

(e) specialist referrals;

(f) hospital admissions.

After complete description of the study to the subjects, written informed consent was obtained.

\section{Statistical analysis}

Data within the above parameters of health care use were not normally distributed and therefore the Mann-Whitney test was used to compare median values between SAD cases and controls, while recognising that non-parametric statistics may be less sensitive to differences between groups. The $\chi^{2}$ test was used to compare the proportions of subjects in the two groups having symptoms, prescriptions and test/investigations, classified into either zero or at least unity on each parameter. This classification was used because the majority of subjects tended to have had none, one or two within each parameter, with only a few having a large number. Because as many as 20 comparisons between SAD cases and controls were sometimes made, $P$ values of $<0.025$ were taken as a conservative indication of statistical significance.

\section{RESULTS}

\section{Screened and interviewed subjects}

Details of the screening and interviewing processes have been given elsewhere (Eagles et al, 1998, 1999). In brief, 34\% of 7937 surgery attenders did not complete a SPAQ, and there are no data to estimate whether these non-responders would have differed in their likelihood of suffering seasonal morbidity. Of the 505 cases of SAD on the SPAQ, nearly half did not attend for interview before the end of February. People who were not interviewed were significantly younger than those who were (Eagles et al, 1999), presumably reflecting willingness and/or availability to participate, but no other differences were detected.

\section{Patients and controls}

Among the interview-confirmed SAD patients, $21(17 \%)$ were male and 102 $(83 \%)$ were female, with double these numbers and the same percentages for controls. The mean age of patients was 39 years $($ s.d. $=10.8)$ and was the same as that of controls (s.d.=11.0).

\section{Main findings}

Table 1 shows some of the main differences in use of health care services between patients with SAD and controls. Apart from hospital admissions (which were rare in both groups), there was excess use of services on all parameters by the patients with SAD.

\section{Symptoms presented}

Tables 2 and 3 give details of the symptoms presented more often by sufferers of SAD at consultations over 5 years. Table 2 categorises symptoms by bodily system. Nearly $15 \%$ of all recorded symptoms could not be classified reliably, and these were grouped as miscellaneous/unclassifiable. This arose either because the presenting complaint was not sufficiently clearly recorded or, more usually, because the aetiology of the symptom (e.g. nausea, chest pain, fatigue) could not be assigned reliably to a particular bodily system. Patients with SAD presented with symptoms in a greater number of different bodily systems (median 4 (interquartile range $=3-5)$ v. $3(2-4)$ in controls; MannWhitney $P<0.001$ ); $59 \%$, as against $30 \%$ of controls, presented with symptoms in four or more different systems. Table 3

Table I Service use over a 5-year period by patients with seasonal affective disorder (SAD) and by nonseasonal controls

\begin{tabular}{lcccc}
\hline & $\begin{array}{c}\text { Patients with } \\
\text { SAD' }(n=123)\end{array}$ & $\begin{array}{c}\text { Controls } \\
(n=246)\end{array}$ & $\begin{array}{c}\text { 95\% Cl for } \\
\text { differences between } \\
\text { medians }\end{array}$ & $\begin{array}{c}\text { Mann-Whitney } \\
P \text { values }\end{array}$ \\
\hline Primary care consultations & $34(19-48)$ & $23(14-38)$ & $4-12$ & $<0.00 I$ \\
Prescriptions & $28(15-48)$ & $18(10-31)$ & $4-12$ & $<0.00 I$ \\
Tests/investigations & $6(3-12)$ & $4(2-8)$ & $0-2$ & 0.021 \\
Specialist referrals & $3(1-4)$ & $1(0-3)$ & $0-1$ & $<0.001$ \\
Hospital admissions & $0(0-0)$ & $0(0-0)$ & $0-0$ & 0.27 \\
\hline
\end{tabular}

I. Values are medians and interquartile ranges.

Table 2 Symptoms presented (classified by bodily system) over a 5 -year period more commonly by patients with seasonal affective disorder (SAD) than by non-seasonal controls

\begin{tabular}{|c|c|c|c|c|}
\hline \multirow[t]{2}{*}{ Symptom type } & \multicolumn{2}{|c|}{$\begin{array}{l}\text { Median number (interquartile } \\
\text { range) of presentations }\end{array}$} & \multicolumn{2}{|c|}{$\begin{array}{l}\text { Per cent presenting } \\
\text { at least once }\end{array}$} \\
\hline & $\begin{array}{l}\text { Patients with } \\
\text { SAD }(n=123)\end{array}$ & $\begin{array}{l}\text { Controls } \\
(n=246)\end{array}$ & $\begin{array}{l}\text { Patients with } \\
\text { SAD }(n=123)\end{array}$ & $\begin{array}{l}\text { Controls } \\
(n=246)\end{array}$ \\
\hline Gastrointestinal & $2(0-5)^{*}$ & I $(0-3)^{*}$ & 69.9 & 63.0 \\
\hline Psychiatric/psychological & $4(I-I I)^{* * *}$ & $0(0-2)^{* * *}$ & $79.7^{+\dagger \dagger}$ & $45.9^{+\dagger \dagger}$ \\
\hline Urinary & I $(0-3)^{* * *}$ & $0(0-2) * * *$ & $57.7^{\dagger \dagger}$ & $41.1^{\dagger \dagger}$ \\
\hline Musculoskeletal & $4(I-I I)^{*}$ & $3(I-6)^{*}$ & 85.4 & 77.2 \\
\hline Miscellaneous/unclassifiable & $5(2-9) * * *$ & $4(1-7)^{* * *}$ & 92.7 & 89.0 \\
\hline
\end{tabular}

*Mann-Whitney $P<0.025$; ***Mann-Whitney $P \leqslant 0.001 ;{ }^{\dagger \dagger} \chi^{2} P<0.01$ (I d.f.); ${ }^{\dagger \dagger \dagger} \chi^{2} P \leqslant 0.00$ I (I d.f.). 
relates to symptoms that have been linked previously to the presentation of SAD. Among these symptoms, it is reassuring that those of depression, tiredness/lethargy and weight gain/bingeing are more common because these would be regarded as central components of the disorder. Anxiety/panic also are more common, which presumably accounts for the excess of presentations with palpitations. The three types of symptoms that might generally be considered as less clearly linked to SAD but were significantly more common in patients with SAD were pain, infection and premenstrual syndrome.

\section{Prescriptions issued}

Table 4 presents the data on prescriptions issued more often to patients with SAD during the 5 years studied. To be most meaningful, some of these data are shown in prescriptions for a particular bodily system, whereas others are subdivided into more specific types of medication. When prescriptions were grouped by bodily system, patients with SAD received prescriptions covering more of the 12 bodily systems (median 6 (interquartile range $=4-8) \quad v$. 6 (4-7); Mann-Whitney $P=0.006)$; among patients with SAD,

Table 3 Specific symptoms presented over a 5 -year period more often by patients with seasonal affective disorder (SAD) than by non-seasonal controls

\begin{tabular}{|c|c|c|c|c|}
\hline \multirow[t]{2}{*}{ Symptom type } & \multicolumn{2}{|c|}{$\begin{array}{l}\text { Median number (interquartile } \\
\text { ranges) of presentations }\end{array}$} & \multicolumn{2}{|c|}{$\begin{array}{c}\text { Per cent presenting at least } \\
\text { once }\end{array}$} \\
\hline & $\begin{array}{l}\text { Patients with } \\
\operatorname{SAD}(n=123)\end{array}$ & $\begin{array}{l}\text { Controls } \\
(n=246)\end{array}$ & $\begin{array}{l}\text { Patients with } \\
\text { SAD }(n=123)\end{array}$ & $\begin{array}{l}\text { Controls } \\
(n=246)\end{array}$ \\
\hline Pain & $6(2-3)^{* *}$ & $4(I-9)^{* *}$ & 91.1 & 85.8 \\
\hline Infection & $9(4-15)^{* *}$ & $7(3-12)^{* *}$ & 96.7 & 94.3 \\
\hline Tiredness/lethargy & $0(0-1)^{* * *}$ & $0(0-0)^{* * *}$ & $25.2^{\dagger \dagger \dagger}$ & $11 . I^{\dagger+1}$ \\
\hline Weight gain/bingeing & $0(0-0)^{* *}$ & $0(0-0)^{* *}$ & $8.1^{\dagger \dagger}$ & $1.6^{\dagger \dagger}$ \\
\hline Depression & I $(0-4)^{* * *}$ & $0(0-0)^{* * *}$ & $55.3^{i \dagger \dagger}$ & $18.7^{\dagger \dagger \dagger}$ \\
\hline Anxiety/panic & $0(0-2)^{* *}$ & $0(0-1)^{* *}$ & 39.0 & 27.6 \\
\hline Palpitations & $0(0-0)^{* * *}$ & $0(0-0)^{* * *}$ & $4.9^{\dagger \dagger}$ & $0^{\dagger \dagger}$ \\
\hline Premenstrual syndrome & $0(0-0) * * *$ & $0(0-0)^{* * *}$ & $17.1^{\dagger+\dagger}$ & $5.7^{+1+}$ \\
\hline
\end{tabular}

**Mann-Whitney $P<0.01$; ***Mann-Whitney $P \leqslant 0.001 ;{ }^{\dagger \dagger} \chi^{2} P<0.01$ (I d.f.); ${ }^{\dagger \dagger} \chi^{2} P \leqslant 0.001$ (I d.f.).

Table 4 Prescriptions over a 5 -year period issued more often to patients with seasonal affective disorder (SAD) than to non-seasonal controls

\begin{tabular}{|c|c|c|c|c|}
\hline \multirow[t]{2}{*}{ Type of prescription } & \multicolumn{2}{|c|}{$\begin{array}{l}\text { Median number (interquartile } \\
\text { range) of prescriptions }\end{array}$} & \multicolumn{2}{|c|}{$\begin{array}{l}\text { Per cent receiving at least } \\
\text { one prescription }\end{array}$} \\
\hline & $\begin{array}{l}\text { Patients with } \\
\operatorname{SAD}(n=123)\end{array}$ & $\begin{array}{l}\text { Controls } \\
(n=246)\end{array}$ & $\begin{array}{l}\text { Patients with } \\
\text { SAD }(n=123)\end{array}$ & $\begin{array}{l}\text { Controls } \\
(n=246)\end{array}$ \\
\hline Gastrointestinal & I $(0-3)^{*}$ & $0(0-1.25)^{*}$ & 52.0 & 42.7 \\
\hline Cardiovascular & $0(0-I)^{*}$ & $0(0-0)^{*}$ & $32.5^{\dagger}$ & $20.3^{\dagger}$ \\
\hline Respiratory & $0(0-2)^{*}$ & $0(0-1)^{*}$ & 48.8 & 41.9 \\
\hline Hypnotic/anxiolytic & $0(0-1)^{* * *}$ & $0(0-0) * * *$ & $30.9+1 \dagger$ & $15.5^{\dagger+\dagger}$ \\
\hline Antidepressant & $\mathrm{I}(0-5)^{* * *}$ & $0(0-0)^{* * *}$ & $54.5^{\dagger \dagger \dagger}$ & $20.3^{1+\dagger}$ \\
\hline Analgesic & $\mathrm{I}(0-3)^{* * *}$ & $0(0-2)^{* * *}$ & $66.7^{7 \dagger \dagger}$ & $47.6^{\dagger+\dagger}$ \\
\hline Antibiotics & $6(2-12)^{* * *}$ & $4(2-9)^{* * *}$ & 91.9 & 89.0 \\
\hline Sex hormones & $0(0-1)^{* * *}$ & $0(0-0) * * *$ & $35.8^{+1 \dagger}$ & $19.9+\dagger \dagger$ \\
\hline
\end{tabular}

*Mann-Whitney $P<0.025$; ***Mann-Whitney $P \leqslant 0.001 ;{ }^{\dagger} \chi^{2} P<0.025$ (I d.f.); ${ }^{\dagger \dagger \dagger} \chi^{2} P \leqslant 0.001$ (I d.f.).

$36 \%$ received prescriptions covering eight or more bodily systems, as compared with $20 \%$ of controls.

\section{Tests and investigations}

Three tests and investigations were carried out more frequently on patients with SAD. Median numbers of full blood counts (Mann-Whitney $P=0.01$ ) and thyroid function tests and erythrocyte sedimentation rates (ESRs) (Mann-Whitney $P=0.002$ for both) were higher. During the 5 years, a greater proportion of patients with SAD had thyroid function tests $(42 \% v .26 \%$, $\chi^{2}=7.92,1$ d.f., $\left.P=0.005\right)$ and ESRs $(33 \%$ v. $18 \%, \chi^{2}=9.55,1$ d.f., $P=0.002$ ).

\section{Specialist referrals}

Three types of specialist referrals were more common among patients with SAD. Reassuringly, psychiatry/psychology referrals were more common for patients with SAD, of whom $27.6 \%$ were referred as against $8.1 \% \quad$ (Mann-Whitney $P<0.001$ ) of controls. The two other specialities that had significantly increased numbers of referrals were physiotherapy (MannWhitney $P=0.005$ ) and gynaecology (Mann-Whitney $P=0.016$ ). Referrals in general were higher among patients with SAD (see Table 1), with $52 \%$ (as against $28 \%$ of controls) having three or more specialist referrals during the 5 -year period.

\section{DISCUSSION}

\section{Summary of findings}

We found that patients with SAD, when compared with two age-matched and gender-matched controls, were much heavier users of health care services; they saw their general practitioners more frequently, they received more prescriptions, they had more tests and investigations and they were referred to more secondary care specialists. Not only were patients with SAD high consumers of health care, but they presented with a greater diversity of different symptoms. Presentations with depression, anxiety, weight gain and lethargy were predictable, but it is more noteworthy that patients with SAD also presented more often with pain, infection and premenstrual syndrome and with symptoms in the urinary, musculoskeletal and gastrointestinal systems. The prescriptions they received reflected not only high rates of presentation but a more diverse 
variety of presenting symptoms than controls. The higher number of tests ordered no doubt reflects diagnostic uncertainties, whereas full blood counts and thyroid function tests are likely to represent appropriate investigation of low mood and/ or tiredness and lethargy. Not only psychiatrists and psychologists, but also physiotherapists and gynaecologists, saw more patients with SAD than they saw controls.

These findings are novel and have significance with regard to the diagnosis, aetiology, comorbidity and management of SAD. These issues are potentially wideranging and the discussion below will attempt to provide a summary rather than do full justice to all of them.

\section{Analogies with service use in non-seasonal depression}

In contrast with SAD, there is a considerable literature on the presentation, the identification, the treatment and the service use of patients with other types of depression in primary care settings. Because these findings constitute comparative data that may be of relevance to our own study, a very brief précis of some relevant points will follow.

Patients with depression present commonly in primary care but their depression often goes undetected (Paykel \& Priest, 1992). Depression frequently is associated with somatic symptoms, especially in primary care settings (Paykel \& Priest, 1992; Brody et al, 1995), and not only do somatic presentations render detection of depression less likely (Brody et al, 1995) but patients with depression who somatise are often particularly frequent consulters in primary care (Portegijs et al, 1996). Depressed patients are generally high consumers of health care services. They are high users of primary care services, they receive more tests and investigations, they have more out-patient visits and they are more often admitted to general hospitals (Simon et al, 1995; Rost et al, 1998). It is striking, however, that within this high demand for health care only a very small proportion of the expense relates to the treatment of the depressive disorder itself (Rost et al, 1998).

There are clear similarities between our study's findings and those for non-seasonal depression. Our own study design did not permit comparison of subjects with SAD against subjects with non-seasonal depression, because our initial selection through screening was based on seasonality of symptoms and not on depression, but such a comparison would be potentially edifying.

\section{Other studies of SAD in primary care}

Our own group previously has reported increased rates of consultation in a smaller comparison of 33 patients each against one control (Eagles et al, 1998), and only when a larger sample was compared with two controls per case could a small autumn and winter excess of consultations be demonstrated among patients with SAD (Andrew et al, 2001). The most striking finding was of an increased rate of consultation by patients with SAD across the months of the years studied.

Only one other study has looked directly at SAD among patients consulting in primary care. Schlager et al (1995) screened a 'convenience sample' of 303 patients attending a family medicine ambulatory centre in New York state during January and February and found that between $8.9 \%$ and $9.6 \%$ (the figure depending upon how the SPAQ was interpreted) satisfied the criteria for SAD. Schlager et al (1995) did not attempt to quantify service use but noted that over half of the patients with SAD reported seasonal pain variation.

Other studies have used less direct methods. Blacker et al (1997) found a peak of primary care presentations with major depression in the winter months, although this did not reach statistical significance, and they suspected that any winter excess in depression might be linked to higher rates of infectious illness. Other studies have found peaks of depressive presentations and antidepressant prescribing in winter (Williams \& Dunn, 1981; Skegg et al, 1986), although such peaks may occur also during the summer months (Skegg et al, 1986). Thus, hitherto there has been little direct evidence about the presentation of $\mathrm{SAD}$, or the burden for care it imposed, in primary care settings.

\section{Comorbidity of SAD}

Anxiety was reported by $72 \%$ of the first series of patients with SAD described by Rosenthal et al (1984) and may be regarded more as a central component of the disorder than as a comorbid phenomenon. Panic disorder previously has been associated with winter depression (Halle \& Dilsaver, 1993) and the fact that there were nine presentations with palpitations among our patients with SAD and none among our controls may further testify to this link.

Premenstrual depression also was reported commonly among Rosenthal et al's (1984) original series, and the relationship between SAD and premenstrual syndrome since has been established further (Maskall et al, 1994). Our patients with SAD presented more commonly than controls with premenstrual problems and were more likely to receive prescriptions for sex hormones. The comorbidity of premenstrual syndrome and SAD may be important to note because seasonal premenstrual syndrome can respond to light therapy (Maskall et al, 1994).

There is good evidence of a link between winter depression and disordered eating, certainly among identified clinical samples (e.g. Blouin et al, 1992). Again, the importance of this association may relate to the response of seasonal bulimia to light therapy (Lam et al, 1994). In our study, although patients with SAD presented with weight gain or binge eating more often than controls did, such presentations were relatively uncommon.

Seasonal pain was reported in Schlager et al's (1995) primary care sample of SAD sufferers and has been described also in about $50 \%$ of a clinical sample of patients with SAD (Dilsaver et al, 1993). Our findings of increased presentations with pain and increased analgesic prescriptions among patients with SAD are in accord with those studies. The relationship between pain and depressed mood, however, may not be a seasonal phenomenon (Von Knorring, 1975).

Patients in our study presented more often than controls did with infections and received more prescriptions for antibiotics, and people with SAD can report that they are especially prone to winter infections. Our findings could be seen as related to 'help-seeking behaviour' or may represent a comorbid biological phenomenon. Immune function certainty fluctuates seasonally (Maes et al, 1994) and reduced winter immune function may be mediated through light deprivation via vitamin D (Rosen et al, 1991); sufferers from winter depression have been shown to receive reduced daylight exposure during winter (Espiritu et al, 1994). 


\section{Other possible reasons for high service use}

Patients with SAD might become high service users because of the SAD itself or because of associated comorbid conditions, but their service use patterns may have other explanations. One prosaic possibility is that depressive symptoms give rise to frequent primary care contact, which facilitates recognition, investigation and treatment of unrelated conditions that otherwise would have remained undiagnosed (Simon et al, 1995). Depression also may lead to an amplification of symptoms and thus to a greater propensity to seek, and to expect, medical assistance (Barsky, 1992). Our own study design was such that, in order to become a confirmed case of SAD, patients had to attend an additional interview and it is possible that this served to select people with SAD who were more focused upon their own health.

Other possible explanations have been explored in a previous paper (Eagles et al, 1998). Hotopf (1994) has suggested that SAD may constitute one component of 'environmental hypersensitivity', a condition characterised by multiple physical symptoms and somatisation and in which media-popularised 'diseases of fashion' can be adopted readily by the patient. Our method of patient identification - they did not self-diagnose and we actively screened and recruited them-perhaps makes this view less plausible. It may be that personality factors are of importance. Sufferers of SAD may be more neurotic, with a tendency to adopt an external locus of control (Murray et al, 1995), and these factors may give rise to an amplification of dysphoria and an increased likelihood of seeking medical advice.

\section{Service implications}

Patients with SAD are consulting frequently in primary care and are high users of health care services but, perhaps partly because of the variety of symptoms with which they present, their SAD goes undiagnosed and untreated; none of the patients in our study had a diagnosis of SAD and in only a very few (from what was recorded in their case records) had the possibility ever been considered. Light therapy has been found to be beneficial for sufferers of SAD and to have few adverse effects (e.g. Eastman et al, 1998). However, study participants often have comprised self-diagnosed

\section{CLINICAL IMPLICATIONS}

Patients with seasonal affective disorder (SAD) make heavy demands on a range of health care services.

- Sufferers of SAD present with a wide variety of physical complaints.

- Generally SAD is not diagnosed, probably contributing to high numbers of tests and prescriptions.

\section{LIMITATIONS}

Patients with SAD were compared only with non-seasonal controls and not with patients suffering from non-seasonal depression.

- Although relatively strict diagnostic criteria for SAD were deployed, it was not possible to validate the diagnosis externally.

- It is not known whether identification and treatment of patients in primary care with SAD influence morbidity or service use.

JOHN M. EAGLES, FRCPsych, Royal Cornhill Hospital, Aberdeen; FIONA L. HOWIE, BSc, ISOBEL M. CAMERON, MA, SAMANTHA M.WILEMAN, PhD, JANE E. ANDREW, MSc, Health Services Research Unit, Foresterhill, Aberdeen; CAROL ROBERTSON, MRCPsych, Royal Cornhill Hospital, Aberdeen; SIMON A. NAll, BSc, Health Services Research Unit, Forester Hill, Aberdeen, UK

Correspondence: Dr John M. Eagles, Royal Cornhill Hospital, Cornhill Road, Aberdeen AB25 2ZH, UK. Tel: 01224 66313I, Fax: 01224 557433, e-mail: john.eagles@gpct.grampian.scot.nhs.uk

(First received 2 March 200I, final revision 29 June 200I, accepted 2 July 200I)

volunteers referred on to specialist centres and this efficacy may not equate to that among patients in primary care. Our own group's trial (Wileman et al, 2001) did not demonstrate superiority of bright white light over dim red light in patients with SAD identified in primary care, some of the subjects being those included in the present study. Therefore, before primary care professionals embark on any attempt at 'assertive identification' of patients with SAD, it would be important to have evidence that treatment does indeed lower morbidity among such patients and perhaps, therefore, results in reduced use of health services.

\section{ACKNOWLEDGEMENTS}

We are grateful to all general practitioners and practice managers who helped to organise the screening and interviewing of their patients. Drs Mysore Dharmendra and Douglas Gray conducted patient interviews. The secretarial work was done by Lana Hadden.

\section{REFERENCES}

American Psychiatric Association (1994) Diagnostic and Statistical Manual of Mental Disorders (4th edn) (DSM-IV). Washington, DC: APA.

Andrew, J. E., Wileman, S. M., Howie, F. L., et al (200I) A comparison of consultation rates in primary care attenders with and without seasonal affective disorder. Journal of Affective Disorders, 62, 199-205.

Barsky, A. (1992) Amplification, somatization and the somatoform disorders. Psychosomatics, 33, 28-34.

Blacker, C.V. R., Thomas, J. M. \& Thompson, C. (1997) Seasonal prevalence and incidence of depressive disorder in a general practice sample: identifying differences in timing by caseness. Journal of Affective Disorders, 43, 4I-52.

Blazer, D. G., Kessler, R. C. \& Swartz, M. S. (1998) Epidemiology of recurrent major and minor depression with a seasonal pattern. The National Comorbidity Survey. British Journal of Psychiatry, 172, 164-167.

Blouin, A., Blouin, J., Aubin, P., et al (1992) Seasona patterns of bulimia nervosa. American journal of Psychiatry, 149, 73-81.

Brody, D. S., Thompson, T. L., Larson, D. B., et al (1995) Recognising and managing depression in primary care. General Hospital Psychiatry, 17, 93-107. 
Dilsaver, S. C., Del Medico, V. J. \& Qamar, A. B. (1993) State-dependent pain in winter depression. British Journal of Psychiatry, 163, 672-674.

Eagles, J. M., Naji, S. A., Gray, D. A., et al (1998) Seasonal affective disorder among primary care consulters in January: prevalence and month by month consultation patterns. Journal of Affective Disorders, 49, $1-8$.

_ , Wileman, S. M., Cameron, I. M., et al (1999) Seasonal affective disorder among primary care attenders and a community sample in Aberdeen. British Journal of Psychiatry, 175, 472-475.

Eastman, C. I., Young, M. A., Fogg, L. F., et al (1998) Bright light treatment of winter depression: a placebocontrolled trial. Archives of General Psychiatry, 55 883-889.

Eastwood, M. R. \& Peter, A. M. (1988) Epidemiology and seasonal affective disorder. Psychological Medicine, 18, 799-806.

Espiritu, R. C., Kripke, D. F., Ancoli-Israel, S., et al (1994) Low illumination experienced by San Diego adults: association with atypical depressive symptoms. Biological Psychiatry, 35, 403-407.

Halle, M. T. \& Dilsaver, S. C. (1993) Comorbid panic disorder in patients with winter depression. American Journal of Psychiatry, 150, 1108-1110.

Hamilton, M. (1967) Development of a rating scale for primary depressive illness. British Journal of Social and Clinical Psychology, 6, 278-296.

Hotopf, M. (1994) Seasonal affective disorder environmental hypersensitivity and somatisation. British Journal of Psychiatry, 164, 246-248.

Joint Formulary Committee (1999) British National Formulary. London: British Medical Association.
Kasper, S., Wehr, T. A., Bartko, J. J., et al (1989) Epidemiological findings of seasonal changes in mood and behavior: a telephone survey of Montgomery County, Maryland. Archives of General Psychiatry, 46 823-833.

Lam, R. W., Goldner, E. M., Solyom, L., et al (1994) A controlled study of light therapy for bulimia nervosa. American Journal of Psychiatry, I5I, 744-750.

Maes, M., Stevens, W., Scharpe, S., et al (1994) Seasonal variation in peripheral blood leukocyte subsets and in serum interleukin- 6 and soluble interleukin-2 and -5 receptor concentrations in normal volunteers. Experientia, 50, 821-829.

Maskall, D. D., Lam, R. W., Misri, S., et al (1994) Seasonality of symptoms in women with late luteal phase dysphoric disorder. American Journal of Psychiatry, I54, |436-144|.

Murray, G. W., Hay, D. A. \& Armstrong, S. M. (1995) Personality factors in seasonal affective disorder: is seasonality an aspect of neuroticism? Personality and Individual Differences, 19, 613-617.

Paykel, E. S. \& Priest, R. G. (1992) Recognition and management of depression in general practice: consensus statement. BMJ, 305, I198-1202.

Portegijs, P. J. M., van der Horst, F. G., Proot, I. M., et al (1996) Somatization in frequent attenders of general practice. Social Psychiatry and Psychiatric Epidemiology, 31, 29-37.

Rosen, L N., Livingston, I. R. \& Rosenthal, N. E. (1991) Multiple sclerosis and latitude: a new perspective on an old association. Medical Hypotheses, 36, 376-378.

Rosenthal, N. E., Sack, D. A., Gillin, C., et al (1984) Seasonal affective disorder: a description of the syndrome and preliminary findings with light therapy. Archives of General Psychiatry, 4I, 72-80.
_, Genhart, M., Sack, D. A., et al (1987) Seasona affective disorder: relevance for treatment and research of bulimia. In Psychology of Bulimia (eds J. I. Hudson \& H.G. Pope), pp. 205-208. Washington, DC: APA.

Rost, K., Zhang, M., Fortney, J., et al (1998)

Expenditures for the treatment of major depression. American Journal of Psychiatry, I55, 883-888.

Schlager, D., Froom, J. \& Jaffe, A. (1995) Winter depression and functional impairment among ambulatory primary care patients. Comprehensive Psychiatry, 36, 18-24.

Simon, G. E., Von Korff, M. \& Barlow, W. (1995) Health care costs of primary care patients with recognised depression. Archives of General Psychiatry 52, 850-856.

Skegg, K., Skegg, D. C. G. \& McDonald, B.W. (1986) Is there seasonal variation in the prescribing of antidepressants in the community? Journal of Epidemiology and Community Health, 40, 285-288.

Terman, M. \& Williams, J. B. W. (1994) SAD assessment tools revised. Light Treatment and Biological Rhythms, 7, 23.

Von Knorring, L. (1975) The experience of pain in depressed patients. Neuropsychobiology, I, I55-165.

Wileman, S. M., Eagles, J. M., Andrews, J. E., et al (200I) Light therapy for seasonal affective disorder in primary care. Randomised controlled trial. British journal of Psychiatry, 178, 311-316.

Williams, J. B.W., Link, M. J., Rosenthal, N. E., et al (1988) Structured Interview Guide for the Hamilton Rating Scale - Seasonal Affective Disorder Version (SIGH-SAD). New York: New York State Psychiatric Institute.

Williams, P. \& Dunn, G. (198I) Cyclical variation in psychotropic drug prescription. Journal of Epidemiology and Community Health, 35, 136-138. 